\title{
Passive monitoring of phenological acoustic patterns reveals the sound of the camouflage grouper, Epinephelus polyphekadion
}

\author{
Noémie Jublier ${ }^{1}$ | Frédéric Bertucci ${ }^{1,2}$ (D) | Loïc Kéver ${ }^{1}$ | Orphal Colleye ${ }^{1}$ | \\ Laurent Ballesta $^{3}$ | Richard S. Nemeth ${ }^{4}$ | David Lecchini ${ }^{2,5}$ | Kevin L. Rhodes ${ }^{6}$ | \\ Eric Parmentier ${ }^{1}$ (D)
}

${ }^{1}$ Université de Liège Laboratoire de Morphologie Fonctionnelle et Evolutive Institut de Chimie - Bâtiment B6c Allée du six août, 114000 Liège, Belgium

${ }^{2}$ EPHE-UPVD-CNRS, USR3278 CRIOBE, Université Paris Sciences et Lettres, Moorea, French Polynesia

${ }^{3}$ Andromède Océanologie, Carnon-Plage, France

${ }^{4}$ Center for Marine and Environmental Studies, University of the Virgin Islands, St. Thomas, US Virgin Islands

${ }^{5}$ Laboratoire d'Excellence 'CORAIL', Perpignan, France

${ }^{6}$ Pacific Marine Science and Conservation, Grass Valley, California

\section{Correspondence}

Eric Parmentier, Université de Liège Laboratoire de Morphologie Fonctionnelle et Evolutive Institut de Chimie - Bâtiment B6c Allée du six août, 114000 Liège Belgium.

Email: parmentier@uliege.be

\section{Funding information}

Contrat de Projet Etat-Polynésie française 2015-2020, LabEx Corail - project Etape, PSL - project Ecora); the National Science Foundation's Virgin Islands Established Program to Stimulate Competitive Research, Grant/Award Number: VI-EPSCoR, NSF1355437; University of Liège and by the Belgian National Fund for Scientific Research (FRS-FNRS), Grant/Award Number: J.0150.16)

\section{Abstract}

1. Passive acoustic monitoring (PAM) is a non-invasive technique that uses hydrophones to monitor populations and ecosystem dynamics. Although many applications of PAM have been developed in recent years, it has never been used to identify a calling marine species.

2. The south pass of Fakarava Atoll, French Polynesia, hosts spawning events of many reef fish species, including the camouflage grouper Epinephelus polyphekadion, with a spawning aggregation abundance exceeding 17000 individuals during the full moons of June and July.

3. The current study aimed to use PAM to distinguish camouflage grouper sounds among the vocal activities of all fish recorded during the aggregation periods. Audio recordings analysis resulted in the identification of 29 sound types, some of which showed diel and lunar patterns.

4. Temporal analysis of these sounds in relation to spawning activities allowed the identification of camouflage grouper calls. These calls can be described as a single pulse or a series of 'boom(s)' with a pulse duration of $\sim 44 \mathrm{~ms}$ and a low dominant frequency of $103 \pm 31 \mathrm{~Hz}$. Video recordings show that the camouflage grouper produces the 'booms' to initialize spawner ascent and to promote synchronous gamete release into the water column.

5. The study highlights for the first time that PAM can be used to identify the previously unknown sound of a fish species. Moreover, we can use it to understand the phenology of some biological activities for improving the resolution of fish biodiversity assessments.

\section{KEYWORDS}

biodiversity, coral, fish, lagoon, monitoring 


\section{1 | INTRODUCTION}

More than 800 fish species from over 100 families have been documented to produce sounds (Bass \& Ladich, 2008; Ladich \& Fine, 2006), but this number is most probably an underestimate (Fine \& Parmentier, 2015). Sounds are produced in different kinds of behavioural contexts, including territorial contexts and food competition or predatory attacks (Hawkins \& Amorim, 2000; Lagardère, Millot, \& Parmentier, 2005; Myrberg, Mohler, \& Catala, 1986). Sound production associated with reproductive behaviour has been the most studied social context in fish bioacoustics, however (Amorim, 2006). These sounds are generally produced by males to attract mates in their territory (Longrie et al., 2013; Parmentier, Kéver, Casadevall, \& Lecchini, 2010), to synchronize spawning events at fish spawning aggregation sites (Erisman \& Rowell, 2017; Lobel, 1992; Rowell, Nemeth, Schärer, \& Appeldoorn, 2015), and to promote the simultaneous release of gametes (Lobel, 2002). As sounds can be used to highlight the phenology of species activity (Ruppé et al., 2015), phenological events such as spawning activities could in turn also be used to identify unknown sounds of vocal species, and may be used to inform conservation management strategies (Rowell et al., 2015).

Fish spawning aggregations (FSAs) are defined as an annual or seasonal gathering of conspecifics for the purpose of reproduction, with higher fish densities than those observed during non-reproductive periods (Domeier \& Colin, 1997). The south pass of Fakarava Atoll, French Polynesia, is known for its fish density and diversity, and because it hosts FSAs of many fish species, e.g. Acanthurus triostegus (the convict surgeonfish) and Lutjanus gibbus (the humpback red snapper) (EP, pers. observ.). Among aggregating species, FSAs of Epinephelidae (groupers) have been the most extensively documented and studied (Sadovy de Mitcheson et al., 2008). In many aggregationforming grouper species, including Epinephelus polyphekadion (the camouflage grouper), individuals make extensive seasonal migrations to form large spawning aggregations at specific locations (Colin, Shapiro, \& Weiler, 1987; Nemeth, 2005; Nemeth, Blondeau, Herzlieb, \& Kadison, 2007; Rhodes, Mcllwain, Joseph, \& Nemeth, 2012; Sadovy, Rosario, \& Román, 1994). The camouflage grouper is a gonochoristic species (Rhodes, Taylor, \& Mcllwain, 2011) that inhabits coral reefs (Heemstra \& Randall, 1993) and forms large (100-1000s of individuals) transient FSAs at specific times and places (Rhodes, Nemeth, Kadison, \& Joseph, 2014; Rhodes \& Sadovy, 2002b, 2002a; Robinson, Aumeeruddy, Jörgensen, \& Öhman, 2008). Within their distributional range, the timing of camouflage grouper FSAs varies with respect to their lunar and seasonal periodicity, with spawning typically occurring at either a new or a full moon (Rhodes \& Sadovy, 2002b). The same reproductive behaviour has been described in several locations, including Palau (Johannes, Squire, Graham, Sadovy, \& Renguul, 1999), Pohnpei (Rhodes \& Sadovy, 2002b, 2002a), the Seychelles (Robinson et al., 2008), the Solomon Islands (Hamilton, Giningele, Aswani, \& Ecochard, 2012), and Papua New Guinea (Hamilton, Potuku, \& Montambault, 2011). Camouflage groupers typically aggregate on spawning sites for around 1-2 weeks each month over a reproductive season of 2-3 months (Rhodes, 2012). During aggregation periods, the density rapidly increases and peaks a few days prior to reproduction. Actual spawning typically occurs over brief periods during one or two successive days, before fish quickly disperse and the density rapidly decreases as fish return to their home reefs (Rhodes et al., 2011; Rhodes \& Sadovy, 2002b). This sequence continues until the reproductive season is concluded.

In Fakarava, previous visual censuses revealed that up to 17000 camouflage groupers come from the surrounding atoll and aggregate to spawn at the mouth of the south pass every year (Mourier et al., 2016; Robbins \& Renaud, 2016). This spawning takes place exclusively during the full moons of June and July. Previous data have shown that at least some groupers use this pass as a spawning aggregation site over multiple years (Mourier, Ballesta, Clua, \& Planes, 2019). The site is within a United Nations Educational, Scientific and Cultural Organization (UNESCO) biosphere reserve, where fishing activities are entirely restricted. As several grouper FSAs have shown a decrease in fish numbers over time or have simply disappeared from some atolls in French Polynesia, the protection of the Fakarava southern pass is critical for the collection of basic functional information to maintain healthy FSAs. This type of information, which includes understanding the phenology of reproducing species using this pass, is thus essential for management actions that will secure the long-term health and persistence of local grouper populations (Mourier et al., 2019). Within the Epinephelidae, acoustic signals have been associated with courtship behaviour and are likely to be related to the spawning activity of many species, including Epinephelus guttatus (the red hind) (Mann, Locascio, Schärer, Nemeth, \& Appeldoorn, 2010), Epinephelus itajara (the goliath grouper) (Mann, Locascio, Coleman, \& Koenig, 2009), Epinephelus marginatus (the dusky grouper) (Bertucci, Lejeune, Payrot, \& Parmentier, 2015), Epinephelus morio (the red grouper) (Nelson, Koenig, Coleman, \& Mann, 2011), Epinephelus striatus (the Nassau grouper) (Schärer, Rowell, Nemeth, \& Appeldoorn, 2012), Mycteroperca bonaci (the black grouper) (Schärer, Nemeth, Rowell, \& Appeldoorn, 2014), Mycteroperca jordani (the Gulf grouper) (Rowell, Aburto-Oropeza, Cota-Nieto, Steele, \& Erisman, 2018), and Mycteroperca venenosa (the yellowfin grouper) (Schärer, Nemeth, et al., 2012). To our knowledge, however, vocalizations have not been assessed for any Pacific grouper species to date, including the camouflage grouper.

Passive acoustic monitoring (PAM) and eco-acoustics can uncover both broad and fine-scale ecological patterns, and can capture natural as well as anthropogenic sound sources and their dynamics simultaneously (Sueur \& Farina, 2015). Acoustics are already used to assess terrestrial biodiversity (Sueur, Pavoine, Hamerlynck, \& Duvail, 2009; Towsey et al., 2014). Until recently, this approach has rarely been used in the marine environment to conduct environmental or biological surveys (Kaplan, Mooney, Partan, \& Solow, 2015; McWilliam \& Hawkins, 2013). PAM involves the use of hydrophones to record all components of underwater soundscapes, including biological sounds. It can provide information on ecosystem functioning by documenting the activities and dynamics of soniferous species over a wide range of temporal and spatial scales (Gannon, 2008; Parmentier et al., 2017; Rountree et al., 2006). It has been used to highlight fish phenology 
(Ruppé et al., 2015), the presence of cryptic species (Kéver, Lejeune, Michel, \& Parmentier, 2016; Picciulin, Kéver, Parmentier, \& Bolgan, 2019), to delimit spawning seasons (Luczkovich, Pullinger, Johnson, \& Sprague, 2008; Picciulin et al., 2013; Rowell et al., 2015), to investigate changes in community richness and diversity (Bertucci, Parmentier, Lecellier, Hawkins, \& Lecchini, 2016; Desiderà et al., 2019), or to locate spawning sites (Lowerre-Barbieri et al., 2008; Walters, Lowerre-Barbieri, Bickford, \& Mann, 2009), for example. Although PAM has been used in many applications over the past few years, it has never been used to identify the call of a focal species in coral reefs.

The present study aimed to record and describe the phenology of vocal activities at the FSA site in Fakarava, and to discern the sound production of the camouflage grouper E. polyphekadion. This goal has been achieved in three steps. First, every fish sound recorded in 2017 in the pass has been discriminated and the most abundant signals were selected, highlighting some temporal variations. Second, this dataset has been compared with diver observations to identify the sound of the focal grouper. Lastly, the selected signals have been validated from video recordings in 2018. This original methodology allowed the validation of the alternative use of PAM in the detection and study of vocal species and provides important conservation applications.

\section{I MATERIALS AND METHODS}

\section{1 | Underwater recordings}

Passive acoustic recordings were made in the south pass of Fakarava Atoll, French Polynesia $\left(-16^{\circ} 52^{\prime} \mathrm{S},-145^{\circ} 46^{\prime} \mathrm{W}\right)$, during the reproductive period of the camouflage grouper in June and July 2017. Two autonomous long-term acoustic recorders (Loggerhead Instruments, Sarasota, FL) connected to HTI96-min hydrophones (sensitivity of $-170 \mathrm{~dB}$ re: $1 \mathrm{~V}$ for a sound pressure of $1 \mu \mathrm{Pa}$ and with a flat frequency response range between $2 \mathrm{~Hz}$ and $30 \mathrm{kHz}$; High Tech Inc., Long Beach, MS) were deployed at two different locations at the aggregation site at 30 and $40 \mathrm{~m}$ of depth. Recorders were secured to a stand $\sim 1 \mathrm{~m}$ above the reef. The devices were programmed to record for $5 \mathrm{~min}$ with 20-min intervals at a sampling rate of $48 \mathrm{kHz}$ (16-bit resolution) from 4 June to 18 June, and for 10 min duration with 30-min intervals from 3 July to 12 July. These recording periods included the full moon of both aggregating months in 2017 (9 June and 9 July). Data were stored on a 64-Gb micro SD memory card and downloaded following retrieval at the end of each recording period.

Additional audio and video recordings were made with a Cyclops camera (Loggerhead Instruments) in June 2018 in the southern pass between 26 June $(09: 30$ h) and 28 June $(13: 29$ h) (the full moon occurred on 27 June). The Cyclops audio recorder $(44.1 \mathrm{kHz}$, 16-bit resolution) triggered simultaneous high-definition video recordings, both of which were scheduled to record for a 30-sec duration at 5 -min intervals.

\section{2 | Recordings analysis}

Data from 2017 were analysed from 4-12 June (i.e. 5 days before and 3 days after the full moon), and from 6-12 July (i.e. 3 days before and 2 days after the full moon). One 5 -min file was analysed every 2 hours. This effort was increased by analysing one 5-min sample every hour at the full moon (9-10 June and 9-10 July). In order to focus on fish vocal activity, audio samples were first down-sampled to a $6-\mathrm{kHz}$ rate and a $20-\mathrm{Hz}$ high-pass filter was further applied. With the higher background noise in the low frequencies in July, a bandpass filter of $50-3000 \mathrm{~Hz}$ was applied. Sounds were detected by visual and aural inspections of spectrograms (fast Fourier transform (FFT), 512 points, Hamming window) using AVISOFT SASLAB PRO 5.2.07 (Avisoft Bioacoustics e.K., Glienicke/Nordbahn, Germany). First, every biological sound that could be attributed to a fish was labelled based on its distinct features, such as the number of pulses, pulse period, frequency, oscillogram shape, etc. (Table 1). Each category referred to a known sound-producing family (e.g. Pomacentridae), identified from existing literature, or to a descriptive name or onomatopoeia (e.g. growl, pulse train, boom) if it could not be identified. Unknown sound types were considered as representative of either a single species or a group of species with similar sounds, such as members of a single fish family. Second, the occurrence of each sound type was plotted against time to identify temporal patterns in their production.

The audio files from 2018 were analysed the same way to validate the results from PAM and, potentially, to link the audio data with behaviours shown in the videos. Temporal and spectral characteristics of the sounds associated with specific behaviours of the grouper were also analysed.

\section{3 | Ethical note}

The positioning and retrieving of the recording devices in this UNESCO biosphere reserve were made under the agreement of the Direction de l'Environnement (DIREN) of French Polynesia and performed by professional divers of the Gombessa IV expedition.

\section{3 | RESULTS}

\section{1 | Detection of the different sound types}

A total of 11524 fish sounds were identified in June and grouped into 29 sound types. On average (mean \pm SD), $122 \pm 33$ sounds, belonging to $14 \pm 2$ sound types were detected every $5 \mathrm{~min}$. Thirteen types of sound representing $95 \%$ of the total sounds (Figure 1) were selected. The 16 remaining sounds, accounting for less than $1 \%$ each, were all grouped in the category 'others' and were removed from the analysis.

Among the 13 sound types selected, two types could be attributed to a fish family (Figure 1), i.e. the Pomacentridae and the Holocentridae (Parmentier, Lecchini, \& Mann, 2016; Parmentier, Vandewalle, Frédérich, \& Fine, 2006). The remaining sound types were 

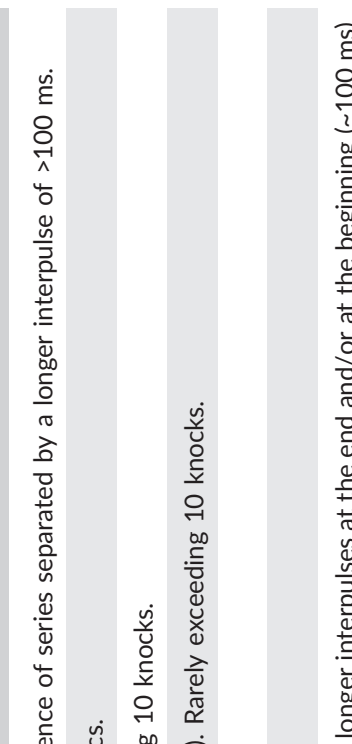

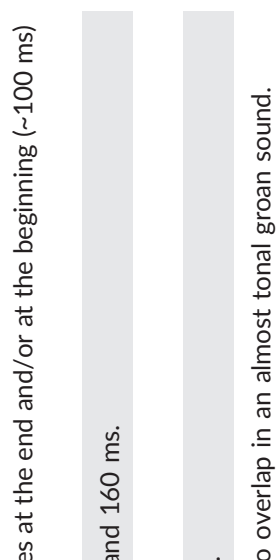
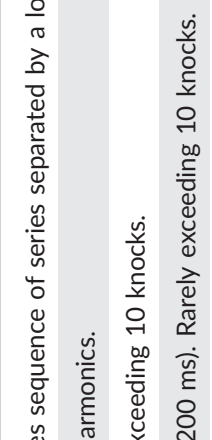

जै

竞

है

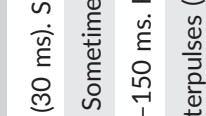

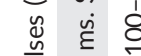

步

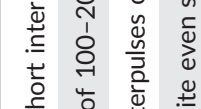

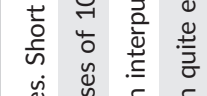

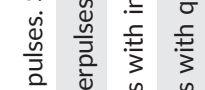

t。

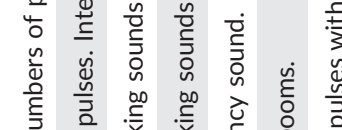

है

है

을

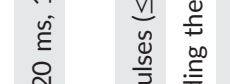

กิ

产

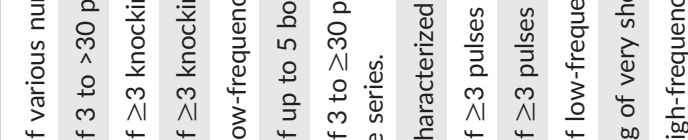

过

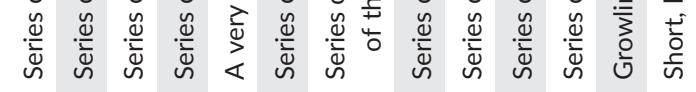

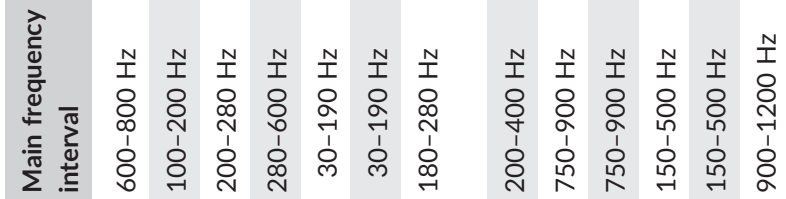

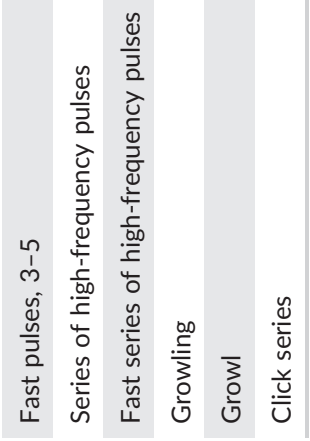




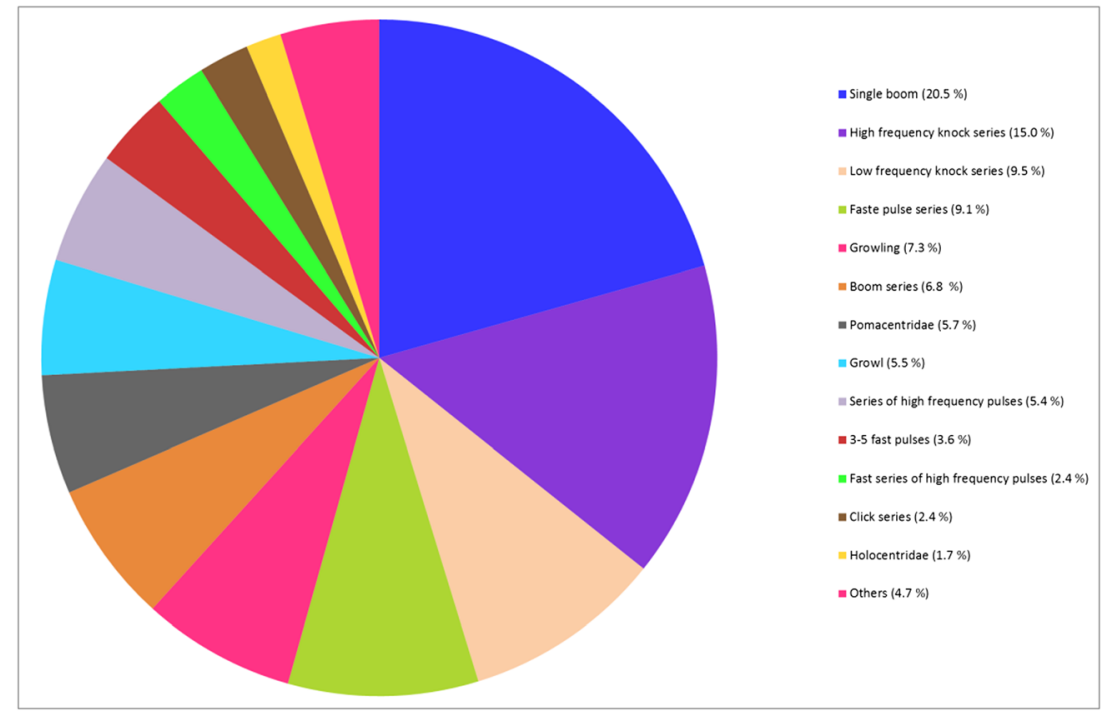

FIGURE 1 Pie chart of the relative proportions of the 13 dominant (95.3\%) and 16 minor (4.7\% combined in 'Others') sound types recorded during 4-12 June 2017 classified as described in Table 1. (See Figure S1 for the oscillogram and spectrogram of each sound type.)

\subsection{Temporal patterns of the sound types}

Pomacentridae sounds and 'click series' showed a diurnal pattern in sound production (Figure 2a, b), whereas the 'high-frequency knock series' and 'high-frequency fast pulse sequences' showed a nocturnal pattern (Figure $2 c, d$ ). In addition to the daily pattern, the 'click series' (Figure $2 \mathrm{~b}$ ) and the 'high-frequency fast pulse sequences' (Figure $2 \mathrm{~d}$ ) varied according to lunar periodicity: the number of 'click series' and 'high-frequency fast pulse sequences', respectively, increase and decrease after the full moon. Additional data will be required to validate these observations, however. The other sound types, excluding booms, did not show any clear diel or lunar patterns during the recorded time period (Figure S2).

\subsection{Sound type attributed to the camouflage grouper}

Among the different sound types, the 'booms' are particularly interesting for their acoustic characteristics (Figure 3) and for their strong relationships with the lunar phase in both June (Figure 4a) and July (Figure 4b) 2017. 'Booms' were recorded from 4 June through to the end of the aggregation period. Before spawning, a higher sound production rate was recorded during the daytime (Figure 4a). The sounds made at night began to increase regularly from 40 to 70 booms per min on the night of the full moon, however, and peaked at 05:00 $\mathrm{h}$ (with 75-90 booms per min). This peak was followed by a dramatic decrease in the number of sounds around sunrise (06.24 h). At that time the rate declined to less than 10 booms per min. Around noon, the boom rate returned to a similar level as observed prior to the full moon. A second peak occurred at 05:00 $\mathrm{h}$ the following day. On
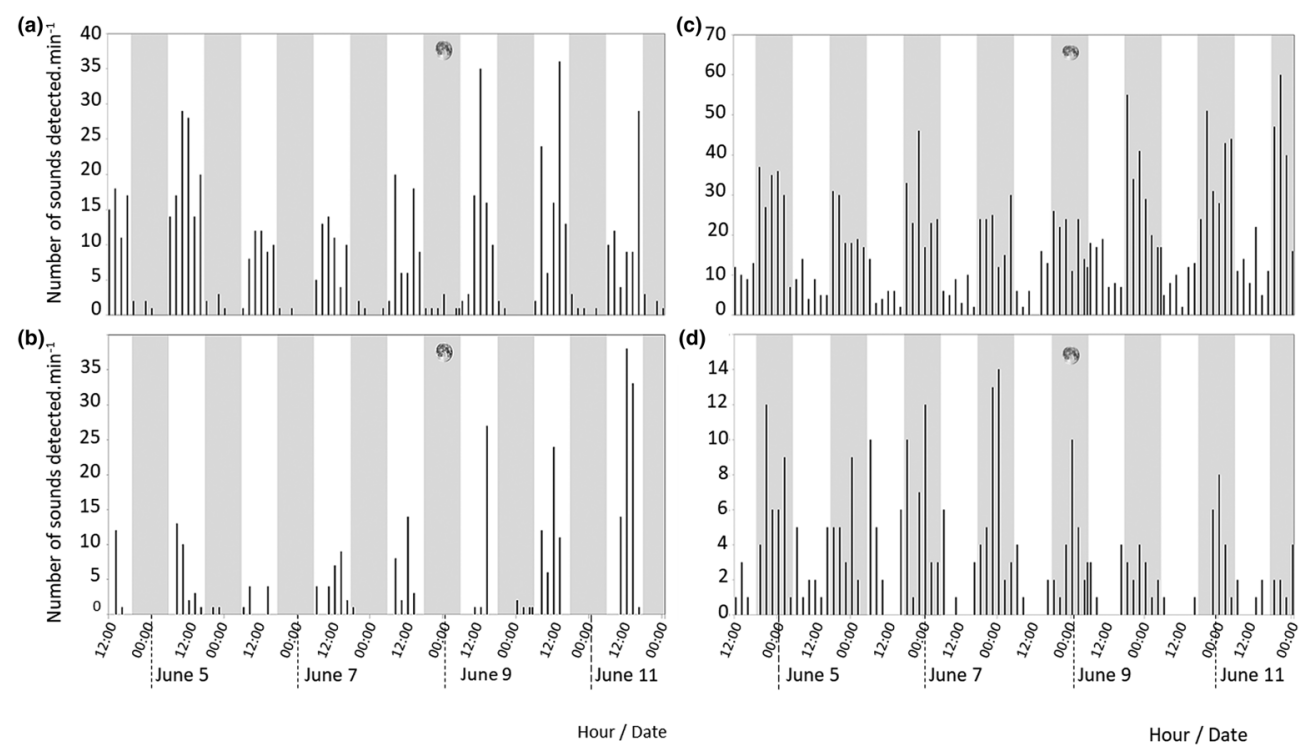

FIGURE 2 Sound types displaying a diel cycle in sound production: (a) Pomacentridae; (b) click series; (c) high-frequency knock series; and (d) high-frequency fast pulse sequence. The grey bands indicate night times. The circle corresponds to the full moon 


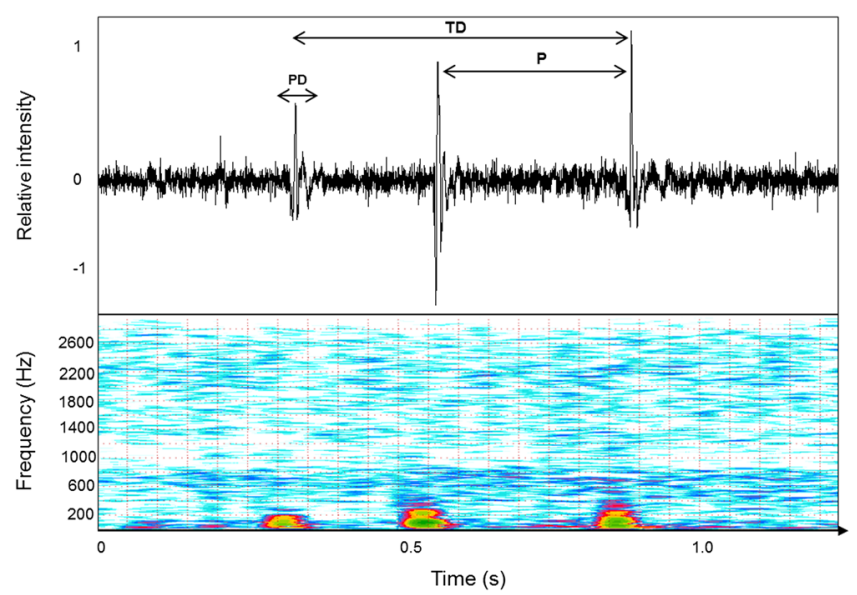

FIGURE 3 'Boom' characteristics. Oscillogram (top) and spectrogram (bottom) of a 'boom series'. The sound intensity colour scale goes from blue through red to green, with green being the highest intensity and blue being the lowest. Abbreviations: P, period; PD, pulse duration; and TD, total sound duration. Note the increasing frequency of each successive boom

subsequent days after the full moon, fewer than 10 booms per min were recorded (Figure 4a). Notably, the occurrence of these two peaks of sonic activity corresponded to observations of spawning activity made by scuba-divers (diving every day prior to the upcoming full moon), i.e. a first small spawning on 9 June and then a major spawning event, together with massive gamete release, on 10 June at c. 05:30 h. Although less intense, the same trend in sound production was observed on both 9 and 10 July 2017. At c. 05:30 h on 9 July, the sound production of the camouflage grouper peaked simultaneously with the diver-observed spawning (Figure 4b). A second smaller peak occurred on 10 July, suggesting a second spawning the following day; however, the actual spawning was not directly observed by the divers. In each case, the most notable change in the data is that at the time of spawning the sound production drops around sunrise, from $80-90$ to 10 booms per min in June and from 50 to 10 booms per min in July (Figure 4).

Booms were mainly produced as single pulses but were also found in series of up to five pulses (Table 2). The pulse duration was $44 \pm 14 \mathrm{~ms}$ $(n=70)$ with a quite irregular period of $321 \pm 213 \mathrm{~ms}(n=36)$. The dominant pulse frequency was $103 \pm 31 \mathrm{~Hz}(n=70)$ (Figure 3).

\subsection{Behaviour potentially linked with the 'booms'}

Two spawning events were observed from the videos made in 2018 , one on 27 June and one on 28 June, both at 06:00 h. A series of booms (or single booms made by several individuals simultaneously) was produced preceding the ascent of camouflage groupers in the
FIGURE 4 Occurrence of the 'boom': (a) 4-12 June 2017; (b) 6-11 July 2017. The grey bands indicates night times; the arrows indicate the spawning events observed by scuba-divers. The circle corresponds to the full moon

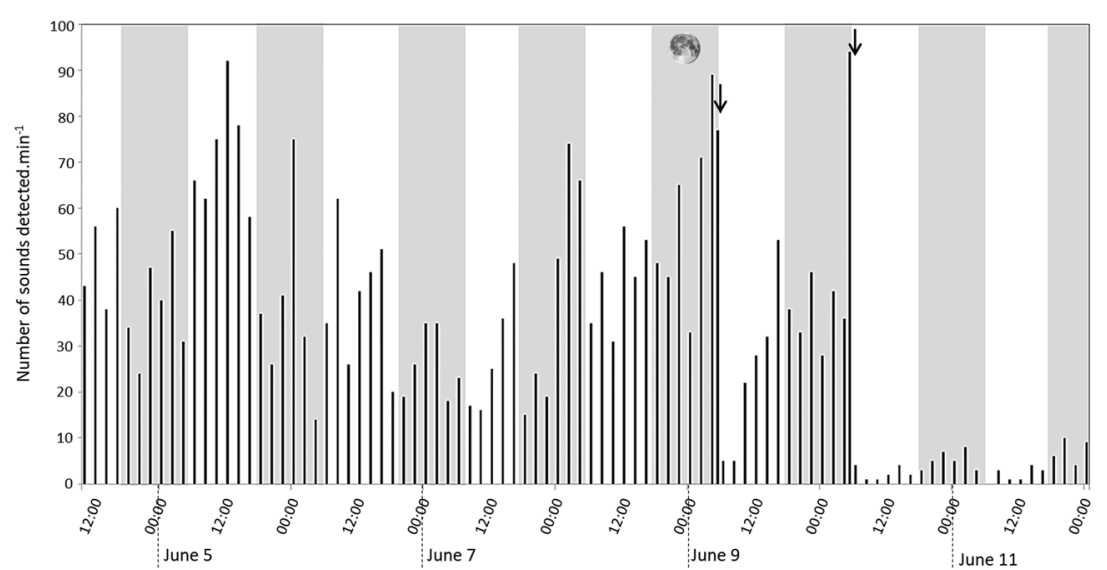

Hour / Date

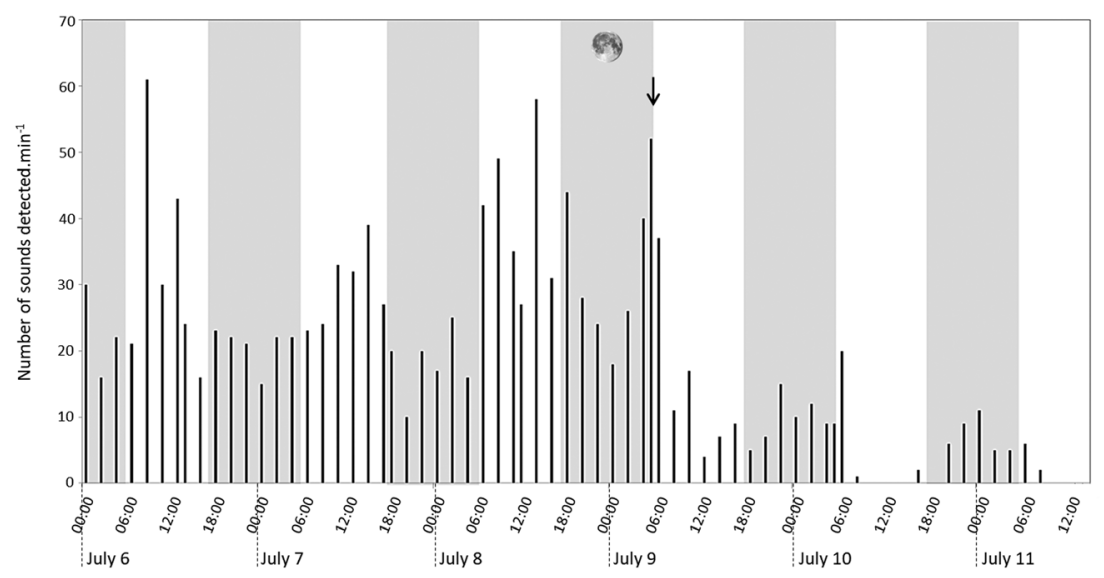

Hour / Date 
TABLE 2 Acoustic characteristics of the 'boom' based on 34 sound samples. See Figure 3 for a representative oscillogram

\begin{tabular}{|lcc|}
\hline & Mean \pm SD & Min.-max. \\
\hline Total duration (ms) & $527 \pm 481$ & $31-1787$ \\
\hline Number of pulse & $2 \pm 1$ & $1-5$ \\
\hline Pulse duration (ms) & $44 \pm 14$ & $20-86$ \\
\hline Pulse period (ms) & $321 \pm 213$ & $69-900$ \\
\hline Dominant frequency $(\mathrm{Hz})$ & $103 \pm 31$ & $32-185$ \\
\hline
\end{tabular}

water column to release their gametes. These booms showed similar acoustic features to the sounds recorded in 2017. The mean pulse duration of the booms recorded in 2018 was $37 \pm 16 \mathrm{~ms}(n=9)$ and the mean dominant frequency was $126 \pm 14 \mathrm{~Hz}(n=9)$.

\section{4 | DISCUSSION}

Coral reef fish often have lengthy spawning seasons with speciesspecific variation in timing and duration that are often related to interactions between temperature and photoperiod (Pankhurst \& Porter 2004), or to lunar phases (Biggs \& Nemeth, 2016; Johannes, 1978). The specific phenology (Colin \& Clavijo, 1988) of spawning events could be related to conditions that may increase the chances of larval survival and can vary among species, with daily, monthly, and annual cycles. In parallel with spawning events, fish can also show sound production patterns with diurnal, crepuscular, or nocturnal calling activities (McCauley \& Cato, 2000; Staaterman, Paris, DeFerrari, Mann, \& Rice, 2014). This study allowed the collection of a large variety of sounds in a marine protected area showing phenological patterns at different temporal scales, from hourly to daily to lunar cycles. This study also noted that the majority of sounds produced by many putative soniferous species remain unknown, however.

Marine soundscapes and their cycles of production may also be informative for understanding biodiversity patterns (Pieretti, Martire, Farina, \& Danovaro, 2017). In Fakarava, temporal cycles were identified for six sound types with a mix of diurnal and nocturnal patterns, that show fishes shared their acoustic space on a temporal basis (Ruppé et al., 2015). Sound types also increased or decreased relative to the full moon, information that can be used to identify sympatric species based on differences in their reproductive activity patterns (Robertson, Green, \& Victor, 1988). Seven dominant sound types did not show any clear pattern during this short-term study and the remaining sounds, accounting each for less than $1 \%$ of the total sounds recorded, may be produced by species that were in very low densities at the time of the recordings, rely less on acoustic signals to communicate, or produce more frequent sounds during other periods of the year. As it seems unlikely that fish produce sounds continuously, longer timeseries of PAM recordings will most likely capture novel sound cycles made by different species. The discrimination of species-specific sounds in the field remains quite difficult, however, as similar acoustic signals can be shared by different species (Colleye, Vandewalle, Lanterbecq, Lecchini, \& Parmentier, 2011; Myrberg, Spanier, \& Ha,
1978; Parmentier, Lecchini, Frederich, Brie, \& Mann, 2009). One approach would be to identify and catalogue the vocalizations of fish species in the south pass of Fakarava and develop a comprehensive repertoire of fish sounds at this important biosphere reserve, which can then be used for comparative purposes at other sites.

The catalogue of identified sounds of different soniferous fish species in Fakarava and elsewhere can be increased by combining underwater field observations and PAM. This was accomplished in 2017 when unique sounds from the fish soundscape were extracted and related to movements of specific fish groups in the field. The booming sound can be attributed to the camouflage grouper for several reasons. First, the sound features (Table 1) are similar to those of other grouper species (Bertucci et al., 2015), and seem to be related to specific behaviours. According to diver observations, the fish started to aggregate at least 9 days before the full moon of June in Fakarava south pass, reaching the highest density a couple of days prior to spawning, similar to studies performed elsewhere (Rhodes \& Sadovy, 2002b). During the full moon, sonic activity peaked in the morning when groupers were observed spawning. Fish, and consequently the booming sounds, rapidly dispersed the day after the spawning event. This spawning period corresponded precisely to the falling tide, with the water outflow favouring egg dispersion into the ocean (Barlow, 1981). These patterns of abundance were also observed by camouflage grouper tracked with acoustic transmitters in Fakarava (Mourier et al., 2019). The frequency of 'booms' around the full moons of July 2017 followed these same temporal trends and declined rapidly after the second spawning event (Figure 4). A similar match in behaviour and sound production was also observed in E. guttatus, where variations in sound levels corresponded to increases in fish density, with maximum levels occurring around spawning at sunset (Rowell et al., 2012). Higher rates of sound production prior to or during spawning have been observed in several fish species, such as $M$. venenosa (Schärer, Rowell, et al., 2012) and Atractoscion nobilis (the white weakfish) (Aalbers, 2008; Aalbers \& Drawbridge, 2008), which could indicate an intensification of the behaviours related to spawning. Moreover, the video recordings suggest that sounds could be emitted to synchronize the spawners, as they were produced just prior to their ascents in the water column. The role of sounds in synchronizing individuals has also been suggested by Bertucci et al. (2015) in E. marginatus, where boom series were associated with behaviours occurring in the initial stage of spawning, preceding vertical ascents. As 'booms' were also recorded in the days before the spawning events, the sounds could be used during other behaviours associated with reproduction, such as territory defence or hierarchic positioning, with male confrontations.

Other groupers, i.e. E. striatus, M. bonaci, and M. venenosa, produce more complex sounds including a series of pulses followed by a long tonal section (Rowell et al., 2018; Schärer et al., 2014; Schärer, Nemeth, et al., 2012; Schärer, Rowell, et al., 2012). Some species also exhibit more specific sound production patterns. For example, E. morio increases its vocalizations in the late afternoon (Nelson et al., 2011), whereas $E$. itajara produces sounds based on a diel cycle, with the highest level between 01:00 and 03:00 h (Mann et al., 2009). The 
camouflage groupers' simpler pattern may be explained by the characteristics of the Fakarava aggregation, which has been reported as being the world's largest, consisting of about 17000 individuals (Mourier et al., 2019, 2016). This aggregation also attracts more than 600 reef sharks (Mourier et al., 2019) that may intercept communication signals (Myrberg, Gordon, \& Klimley, 1976). The increased density of predators may disturb or stress fish species, such that they reduce their vocalizations to reduce predation pressure (Luczkovich et al., 2000; Remage-Healey, Nowacek, \& Bass, 2006). The high density of groupers and sharks at Fakarava may provide unique insights into the dynamics of aggregating species and their sound repertoire at protected FSA sites. The pattern of reduced vocalizations suggests that no complex and repetitive callings are required to communicate at high-density spawning sites, as all of the individuals are in close proximity to one another (Mourier et al., 2019). Other cues can also be used. Males fighting and territory defence behaviour are associated with colour change (Rhodes \& Sadovy, 2002b). Other behaviours involving physical contact rather than acoustic signalling, such as cheek-to-cheek position, pushing at the flanks, snout-to-snout snapping, and sidling have also been described (Johannes et al., 1999; Robinson et al., 2008).

The characterization of the courtship-associated sounds of camouflage grouper in this study indicates that this activity can be acoustically monitored and provides a unique opportunity for the conservation and management of this important species. As has been achieved for E. itajara (Mann et al., 2009) and E. morio (Wall et al., 2014), PAM can help to identify the location and duration of FSA sites. In the groupers E. striatus, M. bonaci, and M. venenosa, for example, the highest rates of courtship-associated sound production occurred prior to sunset and lasted for a period of 10 days, with lunar periodicity over three to five consecutive months (Rowell et al., 2015; Schärer et al., 2014). This information can be used to guide management in terms of defining MPA boundaries or temporary fishing closures during the reproductive season (Nemeth, 2012; Rowell et al., 2015). PAM and other remotesensing equipment could help to elucidate the location of other possible aggregation sites for the camouflage grouper and other aggregating species (Kobara, Heyman, Pittman, \& Nemeth, 2013).

Overall, the study provided further evidence that passive acoustic monitoring is an efficient tool for the survey of soniferous species populations at spawning aggregation sites. Although fish sounds are usually identified by means of recordings performed in tanks and/or by means of video analysis of isolated specimens, this study allowed us to determine for the first time the sound produced by camouflage grouper in the wild by means of PAM. As described above, PAM can help to locate previously unknown FSAs and support the creation of new marine protected areas. It confirms that sounds are an important part of the spawning behaviour of E. polyphekadion, but that silent waters may be required during the reproductive period, which is currently not the case in Fakarava, with excessive boat traffic transporting recreational scuba-divers. Moreover, recordings allowed the identification of clear diel and lunar cycles (Figure 2) in several detected sound types, probably related to the reproductive activity of several fish species, but this requires further investigation. It shows that the continued monitoring of this spawning site will inevitably be beneficial for other sympatric calling species. Monitoring requires the collection of data over long periods, mainly for species like the camouflage grouper that spawn during short periods of the year (June and July). Because of its status as an UNESCO biosphere reserve, the sound data collected in Fakarava Pass provides an initial baseline for soundscapes from a relatively pristine location. We anticipate that data from Fakarava (Figure 4) can be used for comparative purposes with other locations under varying management levels or conservation agendas. It will provide a reference point for determining the levels of produced sounds and can help with both monitoring and determining the size of the grouper aggregation.

\section{ACKNOWLEDGEMENTS}

We thank L. Di lorio and two anonymous referees for their helpful comments on the study. The study was funded by grants from the University of Liège and by the Belgian National Fund for Scientific Research (FRS-FNRS) (J.0150.16). It was also funded in part by a grant to RSN from the National Science Foundation's Virgin Islands Established Program to Stimulate Competitive Research (VI-EPSCoR, NSF-1355437), and in part by grants to DL (Contrat de Projet EtatPolynésie française 2015-2020, LabEx Corail - project Etape, and Université Paris Sciences et Lettres (PSL) - project Ecora). This is contribution no. 202 to the University of the Virgin Islands' Center for Marine and Environmental Studies.

\section{ORCID}

Frédéric Bertucci (D) https://orcid.org/0000-0002-2425-9362

Eric Parmentier (D) https://orcid.org/0000-0002-0391-7530

\section{REFERENCES}

Aalbers, S. A. (2008). Seasonal, diel, and lunar spawning periodicities and associated sound production of white seabass (Atractoscion nobilis). Fishery Bulletin, 106, 143-151.

Aalbers, S. A., \& Drawbridge, M. A. (2008). White seabass spawning behaviour and sound production. Transactions of the American Fisheries Society, 137, 542-550. https://doi.org/10.1577/T04-058.1

Amorim, M. C. P. (2006). Diversity of sound production in fish. Diversity, 1, 71-105.

Barlow, G. W. (1981). Patterns of parental investment, dispersal and size among coral-reef fishes. Environmental Biology of Fishes, 6, 65-85. https://doi.org/10.1007/BF00001801

Bass, A. H., \& Ladich, F. (2008). Vocal-acoustic communication: From behavior to neurons. In A. N. Popper, R. R. Fay, \& J. F. Webb (Eds.), Fish bioacoustics (pp. 253-278). New York: Springer.

Bertucci, F., Lejeune, P., Payrot, J., \& Parmentier, E. (2015). Sounds produced by the dusky grouper (Epinephelus marginatus) during its spawning season in the Mediterranean Sea. Journal of Fish Biology, 87, 400-421. https://doi.org/10.1111/jfb.12733

Bertucci, F., Parmentier, E., Lecellier, G., Hawkins, A. D., \& Lecchini, D. (2016). Acoustic indices provide information on the status of coral reefs: An example from Moorea Island in the South Pacific. Scientific Reports, 6, 33326. https://doi.org/10.1038/srep33326

Biggs, B. S., \& Nemeth, R. S. (2016). Spatial and temporal movement patterns of two snapper species at a multi-species spawning aggregation. 
Marine Ecology Progress Series, 558, 129-142. https://www.int-res. com/abstracts/meps/v558/p129-142/

Colin, P. L., \& Clavijo, I. E. (1988). Spawning activity of fishes producing pelagic eggs on a shelf edge coral reef, southwestern Puerto Rico. Bulletin of Marine Science, 43, 249-279. https://www.ingentaconnect.com/content/umrsmas/bullmar/1988/00000043/00000002/art00006

Colin, P. L., Shapiro, D. Y., \& Weiler, D. (1987). Aspects of the reproduction of two groupers, Epinephelus guttatus and E. striatus in the West Indies. Bulletin of Marine Science, 40, 220-230.

Colleye, O., Vandewalle, P., Lanterbecq, D., Lecchini, D., \& Parmentier, E. (2011). Interspecific variation of calls in clownfishes: Degree of similarity in closely related species. BMC Evolutionary Biology, 11, 365. https://doi.org/10.1186/1471-2148-11-365

Desiderà, E., Guidetti, P., Panzalis, P., Navone, A., Valentini-Poirrier, C. A., Boissery, P., \& Gervaise, C. (2019). Acoustic fish communities: Sound diversity of rocky habitats reflects fish species diversity. Marine Ecology Progress Series, 608, 183-197. https://www.int-res.com/abstracts/ meps/v608/p183-197/

Domeier, M. L., \& Colin, P. L. (1997). Tropical reef fish spawning aggregations: Defined and reviewed. Bulletin of Marine Science, 60, 698-726.

Erisman, B. E., \& Rowell, T. J. (2017). A sound worth saving: Acoustic characteristics of a massive fish spawning aggregation. Biology Letters, 13, 20170656. https://doi.org/10.1098/rsbl.2017.0656

Fine, M. L., \& Parmentier, E. (2015). Mechanisms of sound production. In F. Ladich (Ed.), Sound communication in fishes (pp. 77-126). Wien: Springer.

Gannon, D. P. (2008). Passive acoustic techniques in fisheries science: a review and prospectus. Transactions of the American Fisheries Society, 137, 638-656. https://doi.org/10.1577/T04-142.1

Hamilton, R. J., Giningele, M., Aswani, S., \& Ecochard, J. L. (2012). Fishing in the dark-local knowledge, night spearfishing and spawning aggregations in the Western Solomon Islands. Biological Conservation, 145, 246-257. https://doi.org/https://doi.org/10.1016/j.biocon.2011.11.020

Hamilton, R. J., Potuku, T., \& Montambault, J. R. (2011). Community-based conservation results in the recovery of reef fish spawning aggregations in the Coral Triangle. Biological Conservation, 144, 1850-1858.

Hawkins, A. D., \& Amorim, M. C. P. (2000). Spawning sounds of the male haddock, Melanogrammus aeglefinus. Environmental Biology of Fishes, 59, 29-41. https://doi.org/10.1023/A:1007615517287

Heemstra, P. C., \& Randall, J. E. (1993). FAO species catalogue, Vol. 16. Groupers of the world (Family Serranidae, Subfamily Epinephelinae). An annotated and illustrated catalogue of the grouper, rockcod, hind, coral grouper and lyretail species known to date. FAO Fisheries synopsis. Rome: FAO.

Johannes, R. E. (1978). Reproductive strategies of coastal marine fishes in the tropics. Environmental Biology of Fishes, 3, 65-84. https://doi.org/ 10.1007/BF00006309

Johannes, R. E., Squire, L., Graham, T., Sadovy, Y., \& Renguul, H. (1999). Spawning aggregations of groupers (Serranidae) in Palau. The Nature Conservancy Marine Research Series Publication, 1, 1-144.

Kaplan, M., Mooney, T., Partan, J., \& Solow, A. (2015). Coral reef species assemblages are associated with ambient soundscapes. Marine Ecology Progress Series, 533, 93-107. https://www.int-res.com/abstracts/ meps/v533/p93-107/

Kéver, L., Lejeune, P., Michel, L. N., \& Parmentier, E. (2016). Passive acoustic recording of Ophidion rochei calling activity in Calvi Bay (France). Marine Ecology, 37, 1315-1324. https://doi.org/10.1111/maec.12341

Kobara, S., Heyman, W. D., Pittman, S. J., \& Nemeth, R. S. (2013). Biogeography of transient reef fish spawning aggregations in the Caribbean: $\mathrm{A}$ synthesis for future research and management. Oceanography and Marine Biology: An Annual Review, 51, 281-324.
Ladich, F., \& Fine, M. L. (2006). Sound-generating mechanisms in fishes: A unique diversity in vertebrates. In F. Ladich, S. P. Collin, P. Moller, \& B. G. Kapoor (Eds.), Communication in fishes (pp. 3-34). Enfield, NH: Science Publishers.

Lagardère, J. P., Millot, S., \& Parmentier, E. (2005). Aspects of sound communication in the pearlfish Carapus boraborensis and Carapus homei (Carapidae). Journal of Experimental Zoology Part a: Comparative Experimental Biology, 303, 1066-1074. https://doi.org/10.1002/jez.a.230

Lobel, P. (1992). Sounds produced by spawning fishes. Environmental Biology of Fishes, 33, 351-358. https://doi.org/10.1007/bf00010947

Lobel, P. S. (2002). Diversity of fish spawning sounds and the application of passive acoustic monitoring. Bioacoustics, 12, 286-289. https://doi. org/10.1080/09524622.2002.9753724

Longrie, N., Poncin, P., Denoël, M., Gennotte, V., Delcourt, J., \& Parmentier, E. (2013). Behaviours associated with acoustic communication in Nile tilapia (Oreochromis niloticus). PLoS ONE, 8, e61467. https://doi.org/ 10.1371/journal.pone.0061467

Lowerre-Barbieri, S. K., Barbieri, L. R., Flanders, J. R., Woodward, A. G., Cotton, C. F., \& Knowlton, M. K. (2008). Use of passive acoustics to determine red drum spawning in Georgia waters. Transactions of the American Fisheries Society, 137, 562-575. https://doi.org/10.1577/ T04-226.1

Luczkovich, J. J., Daniel, H. A., Hutchinson, M., Jenkins, T., Johnson, S. E., Pullinger, R. C., \& Sprague, M. W. (2000). Sounds of sex and death in the sea: Bottlenose dolphin whistles suppress mating choruses of silver perch. Bioacoustics, 10, 323-334. https://doi.org/10.1080/09524622. 2000.9753441

Luczkovich, J. J., Pullinger, R. C., Johnson, S. E., \& Sprague, M. W. (2008). Identifying Sciaenid Critical Spawning Habitats by the Use of Passive Acoustics. Transactions of the American Fisheries Society, 137, 576-605. https://doi.org/10.1577/T05-290.1

Mann, D. A., Locascio, J., Schärer, M., Nemeth, M., \& Appeldoorn, R. (2010). Sound production by red hind Epinephelus guttatus in spatially segregated spawning aggregations. Aquatic Biology, 10, 149-154. https://www.int-res.com/abstracts/ab/v10/n2/p149-154/

Mann, D. A., Locascio, J. V., Coleman, F. C., \& Koenig, C. C. (2009). Goliath grouper Epinephelus itajara sound production and movement patterns on aggregation sites. Endangered Species Research, 7, 229-236. https://doi.org/10.3354/esr00109

McCauley, R. D., \& Cato, D. H. (2000). Patterns of fish calling in a nearshore environment in the Great Barrier Reef. Philosophical Transactions of the Royal Society of London. Series B, Biological Sciences, 355, 1289-1293. https://doi.org/10.1098/rstb.2000.0686

McWilliam, J. N., \& Hawkins, A. D. (2013). A comparison of inshore marine soundscapes. Journal of Experimental Marine Biology and Ecology, 446, 166-176. https://doi.org/10.1016/j.jembe.2013.05.012

Mourier, J., Ballesta, L., Clua, E. C., \& Planes, S. (2019). Visitation patterns of camouflage groupers Epinephelus polyphekadion at a spawning aggregation in Fakarava inferred by acoustic telemetry. Coral Reefs, 38, 909-916.

Mourier, J., Maynard, J., Parravicini, V., Ballesta, L., Clua, E., Domeier, M. L., \& Planes, S. (2016). Extreme inverted trophic pyramid of reef sharks supported by spawning groupers. Current Biology, 26, 2011-2016. https://doi.org/10.1016/j.cub.2016.05.058

Myrberg, A. A. J., Gordon, C. R., \& Klimley, A. P. (1976). Attraction of free ranging sharks by low frequency sound, with comments on its biological significance. In A. Schuif, \& A. D. Hawkins (Eds.), Sound reception in fish (pp. 205-228). Amsterdam: Elsevier.

Myrberg, A. A. J., Mohler, M., \& Catala, J. (1986). Sound production by males of a coral reef fish (Pomacentrus partitus): Its significance to females. Animal Behaviour, 34, 913-923. https://doi.org/10.1016/ S0003-3472(86)80077-X 
Myrberg, A. A. J., Spanier, E., \& Ha, S. J. (1978). Temporal patterning in acoustic communication. In E. S. Reese, \& F. Lighter (Eds.), Contrasts in behaviour (pp. 137-179). New York: Wiley and Sons.

Nelson, M., Koenig, C., Coleman, F., \& Mann, D. A. (2011). Sound production of red grouper Epinephelus morio on the West Florida Shelf. Aquatic Biology, 12, 97-108.

Nemeth, R. S. (2005). Population characteristics of a recovering US Virgin Islands red hind spawning aggregation following protection. Marine Ecology Progress Series, 286, 81-97. https://www.ncbi.nlm.nih.gov/ pubmed/16612415

Nemeth, R. S. (2012). Ecosystem aspects of species that aggregate to spawn. In Y. Sadovy de Mitcheson, \& P. Colin (Eds.), Reef fish spawning aggregations: Biology, research and management (pp. 21-55). Dordrecht: Springer.

Nemeth, R. S., Blondeau, J., Herzlieb, S., \& Kadison, E. (2007). Spatial and temporal patterns of movement and migration at spawning aggregations of red hind, Epinephelus guttatus, in the U.S. Virgin Islands. Environmental Biology of Fishes, 78, 365-381. https://doi.org/ 10.1007/s10641-006-9161-x

Pankhurst, N. W., \& Porter, M. C. (2004). Cold and dark or warm and light: Variations on the theme of environmental control of reproduction. Fish Physiology and Biochemistry, 28, 385-389.

Parmentier, E., Di lorio, L., Picciulin, M., Malavasi, S., Lagardère, J. P., \& Bertucci, F. (2017). Consistency of spatiotemporal sound features supports the use of passive acoustics for long-term monitoring. Animal Conservation, 21, 211-220. https://doi.org/10.1111/acv.12362

Parmentier, E., Kéver, L., Casadevall, M., \& Lecchini, D. (2010). Diversity and complexity in the acoustic behaviour of Dacyllus flavicaudus (Pomacentridae). Marine Biology, 157, 2317-2327. https://doi.org/ 10.1007/s00227-010-1498-1

Parmentier, E., Lecchini, D., Frederich, B., Brie, C., \& Mann, D. A. (2009). Sound production in four damselfish (Dascyllus) species: Phyletic relationships? Biological Journal of the Linnean Society, 97, 928-940. https://doi.org/10.1111/j.1095-8312.2009.01260.x

Parmentier, E., Lecchini, D., \& Mann, D. A. (2016). Sound production in damselfishes. In B. Frédérich, \& E. Parmentier (Eds.), Biology of damselfishes (pp. 204-228). Boca Raton, Florida: CRC Press, Taylor \& Francis.

Parmentier, E., Vandewalle, P., Frédérich, B., \& Fine, M. L. (2006). Sound production in two species of damselfishes (Pomacentridae): Plectroglyphidodon lacrymatus and Dascyllus aruanus. Journal of Fish Biology, 69, 491-503. https://doi.org/10.1111/j.1095-8649.2006.0 1117.x

Picciulin, M., Bolgan, M., Codarin, A., Fiorin, R., Zucchetta, M., \& Malavasi, S. (2013). Passive acoustic monitoring of Sciaena umbra on rocky habitats in the Venetian littoral zone. Fisheries Research, 145, 76-81. https:// doi.org/10.1016/j.fishres.2013.02.008

Picciulin, M., Kéver, L., Parmentier, E., \& Bolgan, M. (2019). Listening to the unseen: Passive acoustic monitoring reveals the presence of a cryptic fish species. Aquatic Conservation: Marine and Freshwater Ecosystems, 29, 202-210. https://doi.org/10.1002/aqc.2973

Pieretti, N., Martire, M. L., Farina, A., \& Danovaro, R. (2017). Marine soundscape as an additional biodiversity monitoring tool: A case study from the Adriatic Sea (Mediterranean Sea). Ecological Indicators, 83, 13-20.

Remage-Healey, L., Nowacek, D. P., \& Bass, A. H. (2006). Dolphin foraging sounds suppress calling and elevate stress hormone levels in a prey species, the Gulf toadfish. Journal of Experimental Biology, 209, 4444-4451. https://doi.org/10.1242/jeb.02525

Rhodes, K. L. (2012). Camouflage grouper Epinephelus polyphekadion. In Y. Sadovy de Mitcheson, \& P. L. Colin (Eds.), Reef fish spawning aggregations: Biology, research and management (Vol. 35). Fish \& fisheries Ser. (pp. 422-428). Heidelberg: Springer.

Rhodes, K. L., Mcllwain, J., Joseph, E., \& Nemeth, R. S. (2012). Reproductive movement, residency and fisheries vulnerability of brownmarbled grouper, Epinephelus fuscoguttatus (Forsskål, 1775). Coral Reefs, 31, 443-453. https://doi.org/10.1007/s00338-012-0875-2

Rhodes, K. L., Nemeth, R. S., Kadison, E., \& Joseph, E. (2014). Spatial, temporal, and environmental dynamics of a multi-species epinephelid spawning aggregation in Pohnpei, Micronesia. Coral Reefs, 33, 765-775. https://doi.org/10.1007/s00338-014-1172-z

Rhodes, K. L., \& Sadovy, Y. (2002a). Reproduction in the camouflage grouper (Pisces: Serranidae) in Pohnpei, federated states of Micronesia. Bulletin of Marine Science, 70, 851-869.

Rhodes, K. L., \& Sadovy, Y. (2002b). Temporal and spatial trends in spawning aggregations of camouflage grouper, Epinephelus Polyphekadion, in Pohnpei, Micronesia. Environmental Biology of Fishes, 63, 27-39. https://doi.org/10.1023/A:1013840621820

Rhodes, K. L., Taylor, B. M., \& Mcllwain, L. J. (2011). Detailed demographic analysis of an Epinephelus polyphekadion spawning aggregation and fishery. Marine Ecology Progress Series, 421, 183-198. https://www. int-res.com/abstracts/meps/v421/p183-198/

Robbins, W. D., \& Renaud, P. (2016). Foraging mode of the grey reef shark, Carcharhinus amblyrhynchos, under two different scenarios. Coral Reefs, 35, 253-260. https://doi.org/10.1007/s00338-015-1366-z

Robertson, D. R., Green, D. G., \& Victor, B. C. (1988). Temporal coupling of production and recruitment of larvae of a caribbean reef fish. Ecology, 69, 370-381. https://doi.org/10.2307/1940435

Robinson, J., Aumeeruddy, R., Jörgensen, T. L., \& Öhman, M. C. (2008). Dynamics of camouflage (Epinephelus polyphekadion) and brown marbled grouper (Epinephelus fuscoguttatus) spawning aggregations at a remote reef site, Seychelles. Bulletin of Marine Science, 83, 415-431.

Rountree, R. A., Gilmore, R. G., Goudey, C. A., Hawkins, A. D., Luczkovich, J. J., \& Mann, D. A. (2006). Listening to fish: Applications of passive acoustics to fisheries science. Fisheries, 31, 433-446. https://doi.org/ 10.1577/1548-8446(2006)31

Rowell, T., Nemeth, R., Schärer, M., \& Appeldoorn, R. (2015). Fish sound production and acoustic telemetry reveal behaviors and spatial patterns associated with spawning aggregations of two Caribbean groupers. Marine Ecology Progress Series, 518, 239-254. https://www. int-res.com/abstracts/meps/v518/p239-254/

Rowell, T., Schärer, M. T., Appeldoorn, R. S., Nemeth, M. I., Mann, D. A., \& Rivera, A. J. (2012). Sound production as an indicator of red hind density at a spawning aggregation. Marine Ecology Progress Series, 462, 241-250. https://www.int-res.com/abstracts/meps/v462/p241-250/

Rowell, T. J., Aburto-Oropeza, O., Cota-Nieto, J. J., Steele, M. A., \& Erisman, B. E. (2018). Reproductive behaviour and concurrent sound production of Gulf grouper Mycteroperca jordani (Epinephelidae) at a spawning aggregation site. Journal of Fish Biology, 94, 277-296. https://doi.org/10.1111/jfb.13888

Ruppé, L., Clément, G., Herrel, A., Ballesta, L., Décamps, T., Kéver, L., \& Parmentier, E. (2015). Environmental constraints drive the partitioning of the soundscape in fishes. Proceedings of the National Academy of Sciences of the United States of America, 112, 6092-6097. https://doi. org/10.1073/pnas.1424667112

Sadovy de Mitcheson, Y., Cornish, A., Domeier, M., Colin, P., Russell, M., \& Lindeman, K. (2008). A global baseline for Spawning Aggregations of reef fish. Conservation Biology, 22, 1233-1244.

Sadovy, Y., Rosario, A., \& Román, A. (1994). Reproduction in an aggregating grouper, the red hind, Epinephelus guttatus. Environmental Biology of Fishes, 41, 269-286. https://doi.org/10.1007/BF02197849 
Schärer, M. T., Nemeth, M., Rowell, T., \& Appeldoorn, R. (2014). Sounds associated with the reproductive behavior of the black grouper (Mycteroperca bonaci). Marine Biology, 161, 141-147. https://doi.org/ 10.1007/s00227-013-2324-3

Schärer, M. T., Nemeth, M. I., Mann, D. A., Locascio, J., Appeldoorn, R. S., \& Rowell, T. J. (2012). Sound production and reproductive behavior of yellowfin grouper, Mycteroperca venenosa (Serranidae) at a spawning aggregation. Copeia, 2012, 135-144. https://doi.org/10.1643/CE-10151

Schärer, M. T., Rowell, T., Nemeth, M. I., \& Appeldoorn, R. S. (2012). Sound production associated with reproductive behavior of Nassau grouper Epinephelus striatus at spawning aggregations. Endangered Species Research, 19, 29-38. https://doi.org/10.1007/s00227-013-2324-3

Staaterman, E., Paris, C., DeFerrari, H., Mann, D. A., \& Rice, A. N. (2014). Celestial patterns in marine soundscapes. Marine Ecology Progress Series, 508, 17-32. https://www.int-res.com/abstracts/meps/v508/ p17-32/

Sueur, J., \& Farina, A. (2015). Ecoacoustics: The ecological investigation and interpretation of environmental sound. Biosemiotics, 8, 493-502. https://doi.org/10.1007/s12304-015-9248-x

Sueur, J., Pavoine, S., Hamerlynck, O., \& Duvail, S. (2009). Rapid acoustic survey for biodiversity appraisal. PLoS ONE, 3, e4065. https://doi.org/ 10.1371/journal.pone.0004065

Towsey, M., Zhang, L., Cottman-Fields, M., Wimmer, J., Zhang, J., \& Roe, P. (2014). Visualization of long-duration acoustic recordings of the environment. Procedia Computer Science, 29, 703-712. https://doi. org/10.1016/j.procs.2014.05.063

Wall, C. C., Simard, P., Lindemuth, M., Lembke, C., Naar, D. F., Hu, C., ... Mann, D. A. (2014). Temporal and spatial mapping of red grouper Epinephelus morio sound production. Journal of Fish Biology, 85, 1470-1488. https://doi.org/10.1111/jfb.12500

Walters, S., Lowerre-Barbieri, S., Bickford, J., \& Mann, D. (2009). Using a passive acoustic survey to identify spotted seatrout spawning sites and associated habitat in Tampa Bay, Florida. Transactions of the American Fisheries Society, 138, 88-98. https://doi.org/10.1577/T07106.1

\section{SUPPORTING INFORMATION}

Additional supporting information may be found online in the Supporting Information section at the end of the article.

How to cite this article: Jublier N, Bertucci F, Kéver L, et al. Passive monitoring of phenological acoustic patterns reveals the sound of the camouflage grouper, Epinephelus polyphekadion. Aquatic Conserv: Mar Freshw Ecosyst. 2020;30:42-52. https://doi.org/10.1002/aqc.3242 